\title{
PROTEKSI KEBAKARAN PADA GEDUNG RAMAYANA MALL SORONG
}

\author{
Sri Yanto \\ Program Studi Teknik Sipil Universitas Muhammadiyah Sorong \\ Jalan Pendidikan No 27 Kota Sorong, Propinsi Papua Barat \\ Email :vhc739@gmail.com
}

\begin{abstract}
ABSTRAK
Kebakaran adalah peristiwa yang menyebabkan banyak kerugian. Kebakaran di gedung bertingkat akan menimbulkan banyak kerugian. Beberapa peristiwa kebakaran di gedung komersial berlantai dua dapat digunakan sebagai referensi mitigasi untuk mengurangi risiko kebakaran. Hotel adalah salah satu bangunan komersial yang memiliki standar keamanan bagi pengunjungya. Salah satu bentuk perlindungan adalah membuat perlindungan untuk bahaya kebakaran. Penelitian ini dilaksanakan di gedung Ramayana Mall Sorong, yang berlokasi di Jl. Jend. A. Klademak, Kec. Sorong, Papua Barat. Dengan penelitian ini, semoga Ramayana Mall dapat menjadi rujukan sistem proteksi kebakaran untuk bangunan komersial lainnya di Sorong. Tujuan penelitian ini adalah untuk menilai kelengkapan fasilitas dan infrastruktur sistem proteksi kebakaran yang tersedia di Ramayana Mall. Metode tersebut melalui proses observasi dan penilaian terhadap 4 parameter keandalan sistem keselamatan gedung, yaitu kelengkapan lokasi, perangkat penyelamat, perlindungan aktif, dan perlindungan pasif dengan mengacu pada Peraturan Menteri Pekerjaan Umum Nomor 26/PRT/M/2008 tentang Persyaratan Teknis Sistem Proteksi Kebakaran pada Bangunan dan Lingkungan Bangunan dan Buku Panduan Inspeksi Bangunan Keselamatan Kebakaran (Pd-T-11-2005-C) dari Badan Penelitian dan Pengembangan Kementerian Pekerjaan Umum dan beberapa Standar Nasional Indonesia terkait. Hasil Keandalan Building Safety System adalah 91,60 yang berarti nilai keandalan bangunan di Ramayana Mall baik. Jadi, bangunan Ramayana Mall dapat digunakan secara optimal dan pengguna bangunan mendapat perlindungan dari bahaya kebakaran.
\end{abstract}

Kata Kunci : Kebakaran, Keandalan Bangunan, Sistem Perlindungan Kebakaran 


\section{PENDAHULUAN}

\section{Latar Belakang}

Kebakaran merupakan suatu permasalahan yang tidak bisa lepas dari manusia. Kerugian yang diakibatkan oleh kebakaran tidak hanya berupa kerusakan bangunan saja, melainkan juga kerugian yang menyangkut moral dan jiwa manusia. Beberapa penyebab kebakaran antara lain adalah rendahnya pemahaman dan kesadaran masyarakat akan bahaya kebakaran, kurangnya kesiapan masyarakat dalam menghadapi dan menanggulangi bahaya kebakaran, sistem penanganan kebakaran yang belum terwujud dan terintegrasi, serta rendahnya prasarana dan sarana sistem proteksi kebakaran bangunan yang memadai.

Kebakaran dapat mengakibatkan kematian, dan dapat pula menyebabkan keruntuhan struktur yang membahayakan. Kegagalan pengendalian kebakaran dalam bangunan seringkali terjadi disebabkan karena unsur desain bangunan yang kurang baik. Dalam Undang - Undang nomor 24 Tahun 2007 disebutkan bahwa bencana kebakaran adalah situasi suatu bangunan atau suatu tempat seperti rumah, pabrik, gedung, dan lain - lain dilanda oleh api yang mengakibatkan adanya korban dan atau kerugian. Bencana kebakaran haruslah dihindari dengan cara diminimalisir potensi yang dapat menimbulkan kebakaran, meminimalisir kebakaran sangat perlu untuk menghindari kerugian materi besar dan korban jiwa. Sebuah gedung harus dilengkapi dengan sistem proteksi yang andal atau memenuhi persyaratan teknis tata bangunan.

Definisi sistem proteksi kebakaran pada bangunan gedung dan lingkungan menurut Peraturan Menteri Pekerjaan Umum No. 26/PRT/M/2008 tentang Persyaratan Teknis Sistem Proteksi Kebakaran pada Bangunan Gedung dan Lingkungan adalah sistem yang terdiri atas peralatan, kelengkapan dan sarana, baik yang terpasang maupun pada bangunan yang digunakan baik untuk tujuan sistem proteksi aktif, sistem proteksi pasif, maupun cara-cara pengelolaan dalam rangka melindungi bangunan dan lingkungannya terhadap bahaya kebakaran. Sistem proteksi kebakaran digunakan untuk mendeteksi dan memadamkan kebakaran sedini mungkin dengan menggunakan peralatan yang digerakkan secara manual dan otomatis.

Menurut Pd-T-11-2005-C tentang Pemeriksaan Keselamatan Kebakaran Gedung, komponen utilitas antara lain adalah:

1. Kelengkapan Tapak, komponennya yaitu sumber air, jalan lingkungan, jarak antar bangunan serta hidran halaman.

2. Sarana Penyelamatan, komponennya yaitu jalan keluar, konstruksi jalan keluar dan landasan helikopter.

3. Sistem Proteksi Aktif, komponennya yaitu deteksi dan alarm kebakaran, siames connection, pemadam api ringan, hidran gedung, sprinkler, sistem pemadam luapan, pengendali asap, deteksi asap, pembuangan asap, lift kebakaran, cahaya darurat dan petunjuk arah, listrik darurat, dan ruang pengendali operasi.

4. Sistem Proteksi Pasif, komponennya yaitu ketahanan api struktur bangunan, kompartemensasi ruang, serta pada perlindungan bukaan.

Tujuan penelitian ini adalah untuk melakukan penilaian kelengkapan sarana dan prasarana sistem proteksi kebakaran yang tersedia di Ramayana Mall Sorong. Penilaian dilakukan berdasarkan Buku Pedoman Pemeriksaan Keselamatan Kebakaran Bangunan Gedung (Pd-T-11-2005-C) dari Badan Penelitian dan Pengembangan Kementerian Pekerjaan Umum dan selanjutnya diolah untuk mendapatkan Nilai Keandalan Sistem Keselamatan Bangunan (NKSKB). 


\section{Tujuan Penelitian}

1. Untuk mengetahui kelayakan sistem proteksi kebakaran yang sudah diterapkan pada Ramayana Mall Sorong.

2. Untuk mengetahui peningkatan kualitas sistem proteksi kebakaran Ramayana Mall Sorong sehingga memenuhi kelayakan bangunan gedung.

\section{STATE OF THE ART}

Adapun penelitian terdahulu yang terkait dengan penelitian ini adalah sebagai berikut :

1. Menurut Tomi Suroto (2011) menyebutkan hasil penelitiannya adalah untuk mewujudkan penyelenggaraan bangunan gedung yang aman terhadap bahaya kebakaran, mulai dari perencanaan, pelaksanaan pembangunan sampai pada tahap pemanfaatan bangunan

2. Menurut Ramzi (2018) menyebutkan hasil penelitiannya adalah Dalam mengevaluasi system proteksi kebakaran pada gedung ini dengan menggunakan acuan yaitu Pemeriksaan Keselamatan Kebakaran Bangunan Gedung yang terdiri dari empat poin yaitu sumber air, sarana penyelamatan, sistem proteksi kebakaran pasif dan sistem proteksi kebakaran aktif.

3. Menurut Bheti Wulandari, Rian Trikomara (2018) Melakukan penelitiannya dengan meninjau kesesuaian sistem proteksi kebakaran pada Ayola First Point Hotel Pekanbaru dengan Peraturan Menteri Pekerjaan Umum Nomor 26 Tahun 2008 sebagai pedoman dalam melakukan penelitian ini.

4. Menurut Muhammad Heri Zulfiar, Akhid Gunawan menyebutkan hasil penelitiannya adalah Nilai Keandalan Sistem Keselamatan sebesar 91,60; yang menunjukkan bahwa kondisi gedung secara menyeluruh termasuk di dalam kategori "Baik". Dengan demikian, bangunan dapat digunakan secara optimal dan pengguna bangunan mendapat perlindungan yang baik dari bahaya kebakaran bangunan.

\section{METODE}

\section{Pengumpulan Data}

Pengumpulan data pada penelitian ini menggunakan 2 cara, yaitu:

\section{Data primer}

Data primer diperoleh dengan cara memeriksa dan mencatat kondisi nyata dari sistem proteksi kebakaran yang ada, baik di dalam maupun di luar gedung Mall, yang meliputi jumlah setiap jenis komponen sistem proteksi kebakaran untuk seluruh bangunan gedung, jumlah setiap jenis komponen sistem proteksi kebakaran pada setiap tingkat, serta jumlah setiap jenis komponen sistem proteksi kebakaran yang rusak/tidak berfungsi.

2. Data sekunder

Data sekunder diperoleh dari beberapa dokumen seperti data gedung dan denah bangunan.

\section{Pengolahan Data}

Data-data yang diperoleh dari pengamatan langsung dan check list di lapangan selanjutnya digunakan untuk mengetahui penerapan komponen utilitas bangunan terhadap bahaya kebakaran berdasarkan Peraturan Menteri Pekerjaan Umum No:26/PRT/M/2008 dan untuk mengetahui nilai keandalan sistem keselamatan bangunan terhadap bahaya kebakaran berdasarkan Peraturan $\mathrm{Pd}-\mathrm{T}-$ 11-2005-C tentang Pemeriksaan Keselamatan Kebakaran Bangunan Gedung. 


\section{REFERENSI}

1. Aris, M., Butudoka, M. A., \& Pristianto, H. (2018). Pengaruh Perubahan Iklim Terhadap Potensi Penutupan Muara Oleh Sedimentasi.

2. Kepmen PU No.10/KPTS/2000 tentang Ketentuan Teknis Pengamanan Terhadap Bahaya Kebakaran di Perkantoran dan Bangunan.

3. Kepmen PU No.10/KPTS/2000. tentang Ketentuan Teknis Pengamanan Terhadap Bahaya Kebakaran di Perkantoran dan Bangunan.

4. Menteri Pekerjaan Umum, (2008), Peraturan Menteri Pekerjaan Umum Nomor : 26/PRT/M/2008 "Pedoman Persyaratan Teknis Sistem Proteksi Kebakaran pada Bangunan Gedung dan Lingkungan”, Kementerian Pekerjaan Umum, Jakarta.

5. Pemeriksaan Keselamatan Kebakaran Bangunan Gedung (Pd-T-11-2005-C).

6. Ramzi. 2018. Sistem Proteksi Kebakaran Pada Gedung Perkantoran Krakatau Steel Jakarta

7. Zulfiar, M. H., \& Gunawan, A. (2018). Evaluasi Sistem Proteksi Kebakaran pada Bangunan Hotel UNY 5 Lantai Di Yogyakarta. Semesta Teknika, 21(1), 65-71. 